University of Nebraska - Lincoln

DigitalCommons@University of Nebraska - Lincoln

Faculty Publications: Department of Entomology

June 1985

\title{
Colorado Potato Beetle (Coleoptera: Chrysomelidae): Expression of Resistance in Solanum berthaultii and Interspecific Potato Hybrids
}

\author{
Robert J. Wright \\ University of Nebraska-Lincoln, rwright2@unl.edu \\ Michael B. Dimock \\ Cornell University \\ Ward M. Tingey \\ Cornell university \\ Robert L. Plaisted \\ Cornell University
}

Follow this and additional works at: https://digitalcommons.unl.edu/entomologyfacpub

Part of the Entomology Commons

Wright, Robert J.; Dimock, Michael B.; Tingey, Ward M.; and Plaisted, Robert L., "Colorado Potato Beetle (Coleoptera: Chrysomelidae): Expression of Resistance in Solanum berthaultii and Interspecific Potato Hybrids" (1985). Faculty Publications: Department of Entomology. 91.

https://digitalcommons.unl.edu/entomologyfacpub/91

This Article is brought to you for free and open access by the Entomology, Department of at DigitalCommons@University of Nebraska - Lincoln. It has been accepted for inclusion in Faculty Publications: Department of Entomology by an authorized administrator of DigitalCommons@University of Nebraska - Lincoln. 


\title{
Colorado Potato Beetle (Coleoptera: Chrysomelidae): Expression of Resistance in Solanum berthaultii and Interspecific Potato Hybrids
}

\author{
ROBERT J. WRIGHT, ${ }^{1}$ MICHAEL B. DIMOCK, WARD M. TINGEY, ${ }^{2}$ \\ AND ROBERT L. PLAISTED ${ }^{3}$
}

Department of Entomology, Cornell University, Ithaca, New York 14853

\begin{abstract}
J. Econ. Entomol. 78: 576-582 (1985)
ABSTRACT A wild potato species, Solanum berthaultii Hawkes, and its interspecific hybrids with the commercial potato, S. tuberosum L., were evaluated for resistance to the Colorado potato beetle (CPB), Leptinotarsa decemlineata (Say) in field and laboratory studies in New York. Field-collected summer adults produced nearly 3-fold more eggs on $S$. tuberosum cv. Katahdin than on S. berthaultii over a 7-day period. Egg masses laid on 'Katahdin' were $61 \%$ larger than those laid on S. berthaultii. In field cage plots of $S$. berthaultii, CPB larval development was retarded and very few larvae survived to adulthood. Densities of overwintered CPB adults and defoliation levels were significantly reduced on S. berthaultii compared with S. tuberosum in open field studies. A hybrid family had intermediate levels of defoliation and adult CPB densities. During the second CPB larval generation, densities of small (first and second instars) and large (third and fourth instars) larvae were reduced 90 and $87 \%$, respectively, on the hybrid family and 96 and $97 \%$, respectively, on S. berthaultii compared with CPB densities on S. tuberosum. In other field studies, three to four applications of insecticides timed by use of action thresholds were sufficient to maintain acceptably low levels of defoliation on three hybrid families, one application was needed on $S$. berthaultii, but three applications failed to control CPB on $S$. tuberosum.
\end{abstract}

THE Colorado potato beetle (CPB), Leptinotarsa decemlineata (Say), is the major limiting factor in potato production in the northeastern and midAtlantic regions of the United States (Gauthier et al. 1981). The widespread occurrence of resistance in CPB to insecticides (Hare 1980, Forgash 1981) indicates a critical need for alternate control tactics. The development of CPB-resistant potato cultivars promises to aid in management of this key pest and to reduce current dependence on insecticides for control of CPB.

The wild Bolivian potato species, Solanum berthaultii Hawkes, is effectively defended against many small-bodied arthropods such as aphids, leafhoppers, flea beetles and spider mites by its secretory trichomes (Gibson and Turner 1977, Tingey and Gibson 1978, Tingey 1981, Tingey and Laubengayer 1981, Tingey and Sinden 1982). Casagrande (1982) reported reduced oviposition by CPB on several accessions of $S$. berthaultii and on an $\mathrm{F}_{2} S$. tuberosum $\times S$. berthaultii clone in laboratory studies. Larval survival and developmental rates were adversely affected by $S$. berthaultii. Similar results were obtained in preliminary field trials, although oviposition was not reduced on the hybrid clone (Casagrande 1982).

\footnotetext{
' Long Island Hortic. Res. Lab., 39 Sound Ave., Riverhead, NY 11901 .

${ }^{2}$ To whom reprint requests should be addressed.

${ }^{s}$ Dept. of Plant Breeding and Biometry.
}

The objective of the studies reported here was to further examine the nature and magnitude of resistance to CPB in $S$. berthaultii, as well as in $S$. tuberosum $\times S$. berthaultii germ plasm produced by the Cornell potato breeding program, by means of laboratory studies, small-plot field studies and field cage evaluations. In previous attempts in Europe to breed for CPB resistance in potatoes, high levels of resistance in early hybrids of $S$. tuberosum and $S$. chacoense and $S$. demissum were lost in later generations as selection for horticultural qualities was intensified (Tingey 1984). Because this phenomenon might also occur in S. tuberosum $\times S$. berthaultii hybrids, we evaluated the most advanced $\left(F_{5}\right.$ and $\left.F_{6}\right)$ populations available.

\section{Materials and Methods}

Description of Plant Material. Three categories of potato germ plasm were used in these studies. All were obtained from the Cornell University potato breeding program as true seed and evaluated in our field trials as separate seedling families, with the exceptions of the vegetatively propagated potato cultivars Katahdin and Chippewa and the $S$. berthaultii clone D622-30.

1) Solanum berthaultii; D624, a seedling family produced by the cross PI 310927-11 $\times$ PI 265858-5, and D622-30, a selection from a seedling family produced by the cross PI $310927-11 \times$ PI 310927-12. The parental clones were selected 
from accessions obtained from the Potato Introduction Station, Sturgeon Bay, Wisc.

2) S. tuberosum; D121, a seedling family obtained from the cross, cv. Hudson $\times$ cv. Katahdin.

3) S. tuberosum $\times$ S. berthaultii; E1355, E1357, F662, F724, four seedling families with $S$. tuberosum cytoplasm. E1355 and E1357 are advanced $\left(\mathrm{F}_{5}\right)$ generations of $\mathrm{cv}$. Hudson $\times S$. berthaultii; proportion of $S$. tuberosum and $S$. berthaultii is 50:50. F662 and F724 are advanced $\left(F_{6}\right)$ generations of $S$. tuberosum, $S$. berthaultii, and $S$. tuberosum spp. andigena; proportion of parentage of F662 is $37.5: 37.5: 25$, respectively, and F724 is 25: 50:25, respectively. Parental clones of $S$. berthaultii were drawn primarily from the following accessions: HHC 4531c, PI 265858.

The four hybrid families were produced from parental clones selected for optimum expression of resistance against the green peach aphid, Myzus persicae (Sulzer), and potato leafhopper, Empoasca fabae (Harris), using bioassay procedures (Tingey et al. 1982) coupled with physical (Tingey and Sinden 1982) and chemical (Ryan et al. 1982) analyses of their glandular trichome properties. None of the parental clones or progenies had been subject to prior selection for resistance to the CPB.

Measurement of Oviposition, Larval Survival, and Development on $S$. berthaultii. The oviposition behavior of CPB on $S$. berthaultii was examined using adults reared from burrowing fourth instars collected in late July from field populations at Freeville, N.Y. Upon emergence, adults were placed on $\mathrm{cv}$. Katahdin plants in screen cages ( 46 by 61 by $94 \mathrm{~cm}$ ) in a rearing room at $26^{\circ} \mathrm{C}$ and 45\% RH. Daylength was $16 \mathrm{~h}$, and was provided by fluorescent lights (Sylvania Gro-lux and General Electric Mainlighter Cool White). After reaching sexual maturity (13 August), adults were randomly divided into two groups of 20 females and 10 males each. One group was transferred to an identical cage containing a young $S$. berthaultii plant (PI 310927) grown from true seed in a peat/vermiculite soil mix supplemented with fertilizer (Osmocote). The second group was transferred to a cage containing a plant of cv. Katahdin of similar age and grown under the same greenhouse conditions. Egg masses were collected at 24$h$ intervals from both cages and the number of eggs and eggs per egg mass recorded for 4 days following the transfer to new host plants and again 7 days later, for a total of five sample dates. On day 4 , new plants were placed in both cages and the old plants removed. Mean number of eggs per egg mass was analyzed by one-way analysis of variance (ANOVA).

Previous laboratory studies (M.B.D. and W.M.T., unpublished data) revealed that CPB cohorts reared from egg hatch to death on $S$. berthaultii suffered higher mortality rates, retarded development, and reduced fecundity compared to cohorts reared on $S$. tuberosum. A cage study was conducted in 1983 to examine the effects of $S$. berthaultii on CPB population dynamics under field conditions. Seed pieces of $S$. tuberosum cv. Katahdin and cuttings of the $S$. berthaultii clone, D622-30, were grown in a peat/vermiculite soil mix supplemented with fertilizer (Osmocote). When plants were 10 to 15 $\mathrm{cm}$ tall (14 June), the pots were placed into the soil (to within $1-3 \mathrm{~cm}$ of the rim) at the Homer C. Thompson Vegetable Research Farm in Freeville, N.Y., and enclosed in steel-frame, fiberglass screen cages ( 2.45 by 2.45 by $1.8 \mathrm{~m}$ tall). Each cage contained six potted plants of one species in two rows, $86 \mathrm{~cm}$ apart, with $61 \mathrm{~cm}$ between plants in each row. Four cage plots were established, two containing cv. Katahdin and two containing clone D622-30, for a total of 12 plants per species. All plants were treated three times (on 21 and 29 June and $7 \mathrm{July}$ ) with chlorothalonil (Bravo 5F) at 2.3 liters of product per ha for control of late and early blight and dinocap (Karathane WD) at $0.4 \mathrm{~kg}$ product per ha to control powdery mildew. Weeds were removed by hand cultivation, and soil compaction was minimized by confining foot traffic to the central alley of each cage.

Each cage was infested on 11 July with 300 neonate CPB larvae (from eggs laid by field-collected adults), placed 50 to each plant with camel hair brushes. The timing of infestation coincided with the peak occurrence of larvae of the first summer brood in a neighboring potato field. The numbers of survivors on each plant and their development stages were recorded twice weekly until 8 August, when all insects remaining above the soil were counted and removed. We continued to collect newly emerged adults on 9,10 , and 15 August to ensure that all surviving insects were accounted for.

Assessment of Resistance in Hybrids. Plants were grown from true seed germinated in a peat/ vermiculite mix. Field plots were established at the Long Island Horticultural Research Laboratory, Riverhead, N.Y. In 1982, three seedling families were evaluated; D121, D624, and E1355. The objective of this study was to evaluate the relative CPB resistance levels of these three families of Solanum germ plasm. Since these families were genetically heterogeneous, we pooled resistance ratings of individual plants within each family to provide a comparative assessment of differences in resistance between families.

Plants were transplanted to field plots on 10 and 11 May when ca. 15 to $20 \mathrm{~cm}$ high. Plot size was 8 rows by $3.7 \mathrm{~m}$, with $0.5 \mathrm{~m}$ between plants in a row and $0.9 \mathrm{~m}$ between rows. Plots were arranged in a randomized complete block design with four replications and each plot was separated from each other by a minimum of $1.5 \mathrm{~m}$ of fallow ground. Fertilization and weed control procedures were similar to those used in commercial potato production because no information is yet available on optimum cultural practices for the hybrids or $S$. berthaultii.

Insecticides were applied to all plots for control 


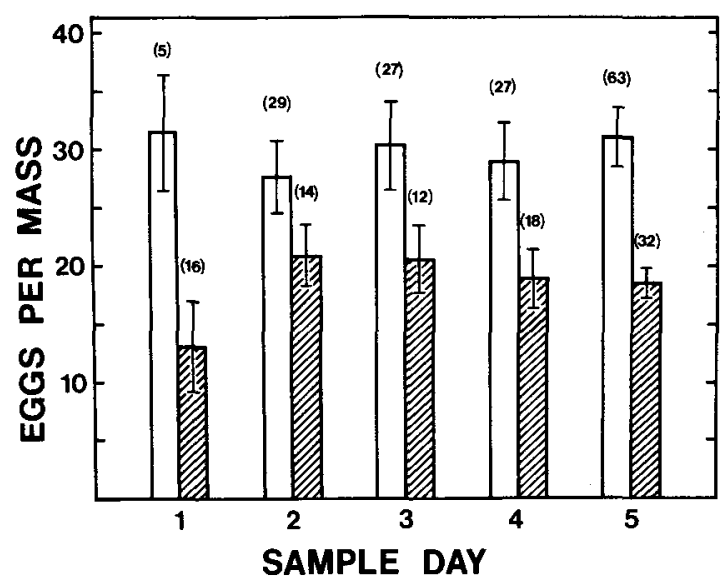

Fig. 1. Mean number of eggs per egg mass collected on five sample dates from $S$. tuberosum cv. Katahdin (open bars) and S. berthaultii PI 310927 (shaded bars). Vertical lines represent $\pm 1 \mathrm{SEM}$, and numbers in parentheses indicate the number of egg masses in each sample.

of CPB on the following dates: fenvalerate and piperonyl butoxide $(0.2$ and $0.9 \mathrm{~kg}[\mathrm{AI}] / \mathrm{ha}$, respectively) on 17 and 21 May and 3 June; oxamyl and endosulfan (1.12 kg [AI]/ha of each) on 26 May, 9 June, and 14 July. Despite these insecticide applications, many plants of the susceptible $S$. tuberosum family, D121, were severely defoliated or killed by early June and plots were replanted on 15 June with seed pieces of cv. Chippewa. These were planted in the central four rows of each D121 plot at $0.3 \mathrm{~m}$ within-row spacing. These plants were sampled for CPB on 9,23 , and 26 July.

Populations of CPB were sampled at intervals of 7 to 14 days by visual examination of individual plants. CPB were categorized as adults, egg masses, small larvae (first and second instars) and large larvae (third and fourth instars). Five to 10 plants chosen at random were examined in each plot; the two outer rows were excluded from sampling. Beginning in July, sampling procedures were modified because differences between families in plant size and growth habit rendered whole plant samples inappropriate for comparative purposes. Lateseason populations were sampled by examining a $0.3 \mathrm{~m}$ vertical section of terminal growth. This provided a comparably sized sample unit for the three germ plasm families, based on visual estimates of plant biomass. Defoliation ratings were made at the same time as counts of CPB. Average defoliation per plot, excluding the two outer rows, was assigned a value from 0 to $5(0,0 \% ; 1,1-10 \%$; $2,11-25 \% ; 3,26-50 \% ; 4,51-90 \% ; 5,91-100 \%)$. CPB counts and defoliation data were combined during the two periods corresponding to the two sample units used (whole plant and $0.3-\mathrm{m}$ section of terminal growth), as well as corresponding to the first and second larval generations, respectively. Data analyzed were plot totals for each sample

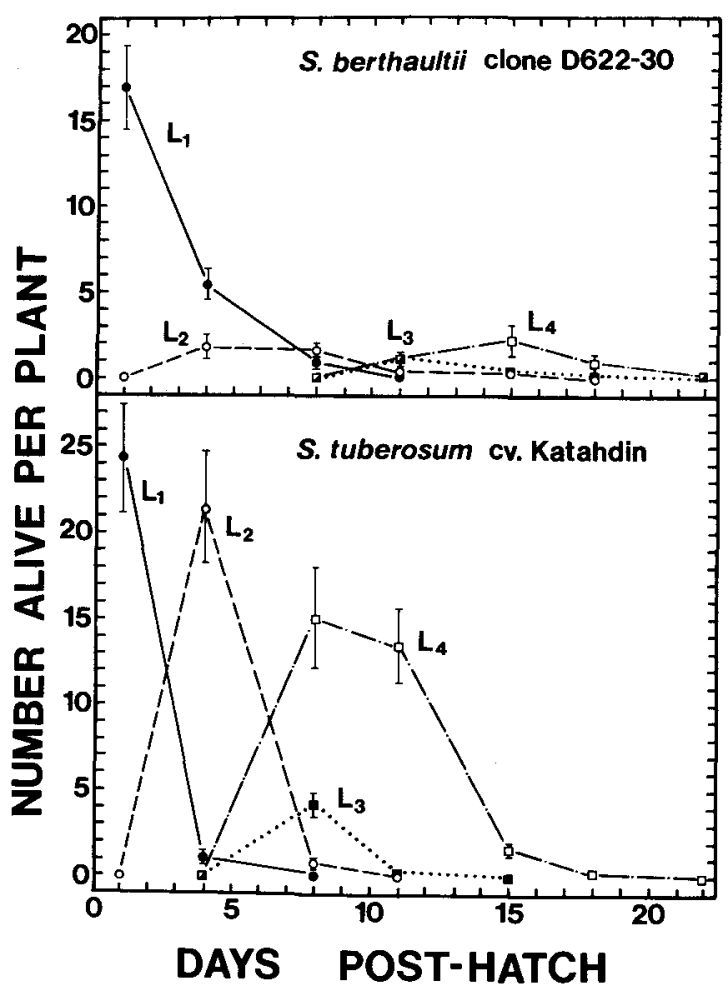

Fig. 2. Survival and development of CPB larvae in field cages containing either $S$. tuberosum cv. Katahdin or S. berthaultii clone D622-30, Freeville, N.Y., July to August 1983. Each point represents the mean number of survivors of each stage per plant $(n=12)$; vertical bars represent \pm 1 SEM and are provided only if large enough to be evident.

date during which a particular life stage was present. CPB population data were transformed to $\log _{10}(x+1)$ before one-way ANOVA as suggested by Harcourt (1963). Raw data of the defoliation ratings were used for ANOVA because our rating scale approximated a pretransformed scale (Little and Hills 1978) for the values encountered.

To avoid early season defoliation of susceptible $S$. tuberosum germ plasm, as was experienced in 1982 , an alternate evaluation procedure was used in 1983. Insecticides were applied to plots when CPB densities exceeded nominal threshold levels (Poston et al. 1983) of 0.5 adults, or 4 small larvae or 1.5 large larvae per stem. By regulating CPB densities at comparable levels on all germ plasm families, we utilized the insecticide need on each germ plasm family to measure relative levels of resistance. Five Solanum germ plasm familiesD121, E1357, F662, F724, and D624-were evaluated in this manner in 1983. Experimental details were similar to 1982 studies except as follows. Plants were transplanted to field plots on 9 June. Plot size was four rows by $3 \mathrm{~m}$ with $0.6-\mathrm{m}$ spacing between plants. Oxamyl and endosulfan (1.12 kg [AI]/ha of each) were applied to each family 
Table 1. Densities of CPB and defoliation ratings on resistant and susceptible potato germ plasm, Long Island, N.Y., 1982

\begin{tabular}{|c|c|c|c|c|c|c|}
\hline \multirow{3}{*}{ Family } & \multirow{3}{*}{ Genotype ${ }^{a}$} & \multicolumn{4}{|c|}{ No. CPB/10 plants ${ }^{b}$} & \multirow{3}{*}{$\begin{array}{c}\text { Defoliation } \\
\text { ratings } \\
(5 / 28-7 / 2)\end{array}$} \\
\hline & & \multirow{2}{*}{$\begin{array}{c}\text { Adults } \\
(5 / 15-7 / 2)\end{array}$} & \multirow{2}{*}{$\begin{array}{l}\text { Egg masses } \\
(5 / 28-7 / 2)\end{array}$} & \multicolumn{2}{|c|}{ Larvae } & \\
\hline & & & & $\begin{array}{c}\text { Small } \\
(6 / 27-7 / 2)\end{array}$ & $\begin{array}{l}\text { Large } \\
(7 / 2)\end{array}$ & \\
\hline D121 & $\mathrm{T}$ & $11 a$ & $13 \mathbf{a b}$ & $6 a$ & $8 a$ & $2.4 a$ \\
\hline E1355 & $\mathrm{T} \times \mathrm{B}$ & $7 \mathrm{~b}$ & $21 a$ & $8 a$ & $6 a$ & $1.6 \mathrm{ab}$ \\
\hline D624 & $\mathbf{B}$ & $3 c$ & $9 \mathrm{~b}$ & $3 \mathbf{a}$ & $2 a$ & $1.2 \mathrm{~b}$ \\
\hline \multirow{3}{*}{ Family } & \multirow{3}{*}{ Genotype $^{a}$} & \multicolumn{4}{|c|}{ No. CPB $/ 10$ terminals $(7 / 9-7 / 23)^{b}$} & \multirow{3}{*}{$\begin{array}{c}\text { Defoliation } \\
\text { ratings } \\
(7 / 9-7 / 23)\end{array}$} \\
\hline & & \multirow{2}{*}{ Adults } & \multirow{2}{*}{ Egg masses } & \multicolumn{2}{|c|}{ Larvae } & \\
\hline & & & & Small & Large & \\
\hline 'Chippewa' & $\mathrm{T}$ & 3 & 2 & $24 a$ & $58 a$ & $2.1 \mathrm{a}$ \\
\hline E1355 & $\mathbf{T} \times \mathbf{B}$ & 1 & 0 & $2 b$ & $8 b$ & $1.2 \mathrm{~b}$ \\
\hline D624 & B & 0 & 0 & $\mathrm{lb}$ & $2 c$ & $1.0 \mathrm{~b}$ \\
\hline
\end{tabular}

a T, S. tuberosum; B, S. berthaultii.

${ }^{b}$ Data transformed by $\log _{10}(x+1)$ before ANOVA; data shown are back transformed means. In a column, means followed by the same letter are not significantly different $(P=0.05$; Duncan's [1955] multiple range test).

$c$ Based on $1-5$ rating scale; see text for description. Ratings followed by the same letter are not significantly different $(P=0.05$; Duncan's [1955] multiple range test).

whenever weekly CPB censuses indicated that the action threshold had been exceeded. This resulted in the following timing and number of treatments: 23 June (D121, F662), 29 June (F662, F724, E1357), 6 July (all families), and 18 July (all families except D624).

Censuses of CPB and measurements of defoliation were made as described for 1982 studies, except that late-season populations were sampled with a single main stem as the sample unit. Late-season $\mathrm{CPB}$ and defoliation data were analyzed by ANOVA as described above and Duncan's (1955) multiple range test $(P=0.05)$ was used for mean separation (Duncan 1955).

\section{Results and Discussion}

Oviposition on S. berthaultii. Total egg production was nearly 3 -fold higher on $S$. tuberosum than on $S$. berthaultii (4,509 versus 1,682 eggs total, respectively). More importantly, in view of our methods for determining field oviposition rates on this species and on hybrids, egg masses collected from $S$. berthaultii were consistently smaller than those laid on S. tuberosum (Fig. 1). Egg masses laid on cv. Katahdin contained an average of 29.4 eggs, significantly greater than the average of 18.3 eggs per mass laid on PI $310927(P=0.001)$. These data suggest that CPB may be physiologically unable to produce eggs at a rate necessary for deposition of the large egg masses. Alternately, females may be more restless on $S$. berthaultii and not remain in one location long enough to deposit large egg masses. The former hypothesis is consistent with our earlier finding that fecundity of females reared from birth on $S$. berthaultii is severely depressed (M.B.D. and W.M.T., unpublished data). A practical implication of the reduction in egg mass size is that resistance ratings based on egg mass counts are more conservative than those based on time-consuming total egg counts.

Larval Survival and Development on $S$. berthaultii. The cage plot study provided considerable evidence of the negative impact of $S$. berthaultii on CPB population dynamics under field conditions. Only $2 \%$ of the neonate larvae placed on S. berthaultii clone D622-30 emerged as adults, compared with $41 \%$ survival to adulthood on $S$. tuberosum, cv. Katahdin. Larval development was substantially retarded in the $S$. berthaultii cages (Fig. 2). On 19 July, 8 days after hatching and infestation, $74 \%$ of the surviving larvae on S. tuberosum had reached the final stadium $\left(\mathrm{L}_{4}\right)$, while none on $S$. berthaultii had entered the third stadium. Indeed, the peak occurrence of fourth instars was not observed in the $S$. berthaultii cages until 26 July. A similar delay was observed in adult emergence; adults reared on cv. Katahdin emerged and began to oviposit 7 days before any adults were discovered in the $S$. berthaultii cages. This finding is consistent with an earlier observation (M.B.D. and W.M.T., unpublished data) that females reared on cv. Katahdin oviposit ca. 2 weeks earlier than females of the same age reared on $S$. berthaultii.

The net effects of accumulated developmental and reproductive delay, both within and across generations, will be to reduce the rate of population growth and to limit the number of generations successfully completed during a single growing season. Retarded development might also prolong the period of exposure of vulnerable larvae to both natural and applied control agents. Latheef and Harcourt (1974) reported that CPB population growth on tomato, Lycopersicon esculentum L., was sufficiently delayed so as to enable the parasitoid, Doryphorophaga doryphorae (Riley) to exert a directly density-dependent, stabilizing influence in a manner not observed among beetle 

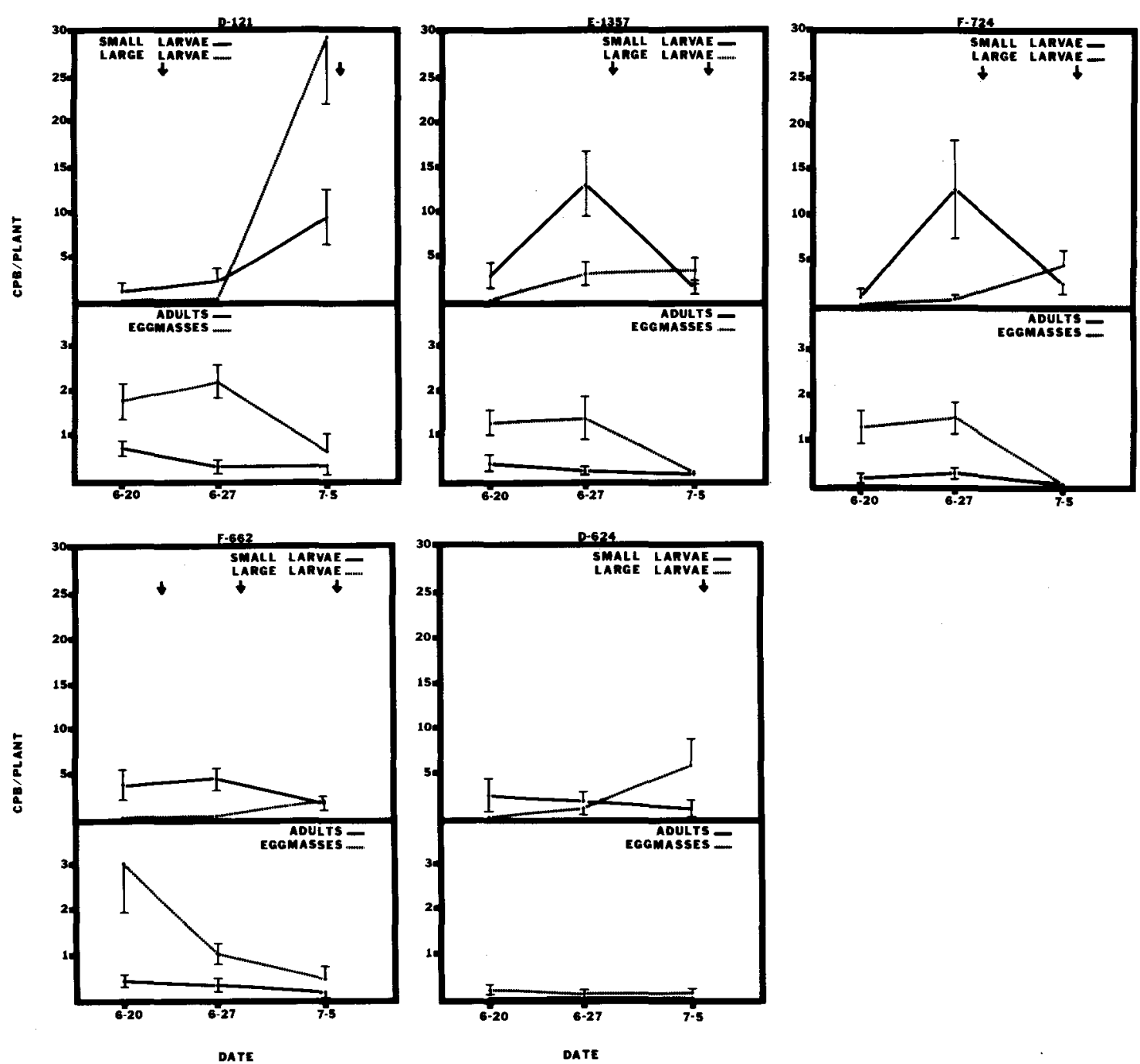

Fig. 3. Densities of CPB life stages on five different potato families, Long Island, N.Y., 1983. Arrow indicates application of oxamyl-endosulfan (1.12 kg [AI]/ha of each). Height of vertical bar around mean equal to $1 \mathrm{SEM}$. An additional insecticide application (not shown on graphs) was applied to all families (except D624) on 18 July.

populations on potatoes. Plant resistance of the type exhibited by $S$. berthaultii might, therefore, be expected not only to slow CPB population increase and limit or prevent the occurrence of second or third summer broods (which frequently cause the most severe losses to growers), but also to augment the efficacy of other control tactics.

Thoughtful integration of such plant resistance into a broad-based integrated approach to potato pest management should minimize selection for virulent host plant biotypes of $L$. decemlineata, ${ }^{4}$ a serious concern in view of the demonstrated occurrence of CPB host races (Hsiao 1978) and the

\footnotetext{
4 Groden, E., and R. A. Casagrande. 1984. Colorado potato beetle, Leptinotarsa decemlineata (Say) (Coleoptera: Chrysomelidae) overcomes Solanum berthaultii resistance. Paper presented at the ESA Eastern Branch Meeting, 27 September 1984, Hershey, $\mathrm{Pa}$.
}

success with which some populations of this insect have overcome nearly all available potato insecticides.

Expression of Resistance in Hybrids. In 1982, the fewest overwintered adults were observed on $S$. berthaultii (D624), intermediate numbers were found on the $S$. tuberosum $\times S$. berthaultii hybrid (E1355) and the most adults were on $S$. tuberosum (D121) (Table 1). Significantly fewer egg masses were laid on D624 than on E1355, while egg mass densities did not differ between E1355 and D121. Densities of first generation larvae were similar on the three germ plasm families.

Feeding activity (as measured by defoliation ratings) of the overwintered adults and first larval generation most closely paralleled densities of adults; larval densities did not differ significantly during this period. Defoliation scores of the resistant (D624) and susceptible (D121) families were 
Table 2. Densities of CPB and defoliation ratings on resistant and susceptible potato germ plasm, Long Island, N.Y., 1983

\begin{tabular}{|c|c|c|c|c|c|}
\hline \multirow{3}{*}{ Family } & \multirow{3}{*}{ Genotype $^{a}$} & \multicolumn{4}{|c|}{ No. CPB per five stems, 18 July $b c$} \\
\hline & & \multirow{2}{*}{ Adults } & \multirow{2}{*}{$\begin{array}{c}\text { Egg } \\
\text { masses }\end{array}$} & \multicolumn{2}{|c|}{ Larvae } \\
\hline & & & & Small & Large \\
\hline D121 & $\mathrm{T}$ & $23 a$ & $3 \mathbf{a}$ & 1 & 1 \\
\hline E1357 & $\mathrm{T} \times \mathrm{B}$ & $6 b$ & $2 a$ & 0 & 0 \\
\hline F662 & $\mathrm{T} \times \mathrm{B}$ & $9 a b$ & $4 a$ & 0 & 0 \\
\hline F724 & $\mathrm{T} \times \mathrm{B}$ & $9 a b$ & $4 a$ & 0 & 1 \\
\hline \multirow[t]{3}{*}{ D624 } & B & 0 & 0 & 0 & 0 \\
\hline & & \multicolumn{4}{|c|}{ Defoliation rating ${ }^{b d}$} \\
\hline & & \multicolumn{2}{|c|}{6 July } & \multicolumn{2}{|c|}{18 July } \\
\hline $\mathrm{D} 121$ & $\mathrm{~T}$ & \multicolumn{2}{|c|}{$2.25 \mathrm{a}$} & \multicolumn{2}{|c|}{$3.25 \mathrm{a}$} \\
\hline E1357 & $T \times B$ & \multicolumn{2}{|c|}{$1.0 \mathrm{~b}$} & \multicolumn{2}{|c|}{$1.0 \mathrm{~b}$} \\
\hline F662 & $\mathbf{T} \times \bar{B}$ & \multicolumn{2}{|c|}{$1.0 \mathrm{~b}$} & \multicolumn{2}{|c|}{$1.0 \mathrm{~b}$} \\
\hline F724 & $T \times B$ & \multicolumn{2}{|c|}{$1.0 \mathrm{~b}$} & \multicolumn{2}{|c|}{$1.0 \mathrm{~b}$} \\
\hline D624 & B & \multicolumn{2}{|c|}{$0.5 b$} & \multicolumn{2}{|c|}{$0.5 \mathrm{c}$} \\
\hline
\end{tabular}

a T, S. tuberosum; B, S. berthaultit.

${ }^{b}$ In a column, means followed by the same letter are not significantly different ( $P=0.05$; Duncan's [1955] multiple range test).

${ }^{c}$ Data shown are back transformed from $\log _{10}(x+1)$.

$d 0$ to 5 , Defoliation scale (see text for description).

significantly different, while those of the hybrid (E1355) were intermediate (Table 1). Ovipositional behavior by overwintered adult CPB (Table 1) was comparable with that reported in the field studies of Casagrande (1982); i.e., oviposition rates on the hybrid were similar to those on S. tuberosum. Other comparisons with Casagrande (1982) are difficult because the use of insecticides to protect plants from complete defoliation suppressed the first larval CPB generation.

Results obtained during the second CPB generation (9-23 July) were more dramatic (Table 1). Densities of all CPB stages on S. berthaultii (D624) and the hybrid (E1355) were less than those on the S. tuberosum cultivar. Larval populations were affected to the greatest degree; densities of small larvae were reduced $90 \%$ on E1355 and $96 \%$ on D624, and large larvae were reduced $87 \%$ on E1355 and $97 \%$ on D624 compared to the cv. Chippewa. Alternately, the hybrid expressed a significant degree of resistance inherited from $S$. berthaultii; densities of small larvae were similar on both D624 and E1355. While the number of large larvae was somewhat greater on E1355 than on D624, defoliation of the hybrid was no greater than that of S. berthaultii (Table 1).

It is possible that the cv. Chippewa plants used to replace the defoliated D121, being younger than the D624 or E1355 plants, received more oviposition than would have occurred on older plants (de Wilde et al. 1969). In this case, the replacement plants would not be an appropriate standard for comparison of larval populations with E1355 and D624. However, the hybrid retained much of the resistance inherited from its $S$. berthaultii parent. Furthermore, Casagrande (1982) has previ- ously demonstrated that $S$. berthaultii significantly reduced CPB oviposition, development rates and larval survival compared to $S$. tuberosum.

Where insecticides were applied according to CPB action thresholds to open field plots of five Solanum germ plasm families, insecticide use was inversely related to plant resistance levels (Fig. 3). Despite these differences in insecticide usage, CPB populations during the first generation were highest on S. tuberosum (D121), intermediate on the three hybrid families (E1357, F662, F724) and least on S. berthaultii (D624) (Fig. 3). Insecticide treatments failed to provide adequate control of adults and larvae on D121 in July, resulting in substantial defoliation (Fig. 3 and Table 2).

This study demonstrated that three to four applications of oxamyl-endosulfan on the S. tuberosum $\times S$. berthaultii hybrids were sufficient to maintain CPB at acceptable levels and one application was needed on $S$. berthaultii, while three applications of oxamyl-endosulfan failed to provide control on the $S$. tuberosum family. The inadequate control on $S$. tuberosum is indicated by both higher defoliation levels and higher CPB densities (Table 2 and Fig. 3). Two additional insecticide applications may have been necessary to provide CPB control comparable to that achieved on the hybrids. This estimate is based on the density of the populations observed on D121 and the degree of control achieved with oxamyl-endosulfan at labelled rates on these insecticide resistant CPB populations. By these criteria, the resistance of the hybrids substituted for 20 to $40 \%$ of the estimated insecticide need on the susceptible $S$. tuberosum family, while the resistance of the $S$. berthaultii family substituted for $80 \%$ of the estimated insecticide need on $S$. tuberosum.

Free choice studies in small plots, such as those reported here, are useful in identifying resistant germ plasm and provide comparative data on relative resistance levels of different germ plasm families. From data presented here and by Casagrande (1982) S. berthaultii and S. tuberosum $\times$ $S$. berthaultii hybrids clearly have useful levels of resistance to CPB.

Although the impact of $S$. berthaultii on CPB population dynamics has been studied here and by Casagrande ${ }^{5}$, we did not investigate the effect of hybrid germplasm on CPB population dynamics because of limitations in the sampling methods as well as the confounding effect of interplot dispersal which occurs in small plot field studies of CPB.

\section{Acknowledgment}

This research was supported, in part, by a grant from the International Potato Center, Grant No. 780054 from the Competitive Research Grants Office (USDA-SEA), a grant from Suffolk County, N.Y., and the Cornell Univ.

\footnotetext{
${ }^{5}$ Casagrande, R. A. 1983. Colorado potato beetle population dynamics in Solanum berthaultii. Paper presented at the ESA Eastern Branch Meeting, 21 September 1983, Providence, R.I.
} 
Agric. Exp. Stn. A publication of the Cornell Univ. Agric. Exp. Stn., New York State College of Agriculture and Life Sciences, a statutory College of S.U.N.Y.

\section{References Cited}

Casagrande, R. A. 1982. Colorado potato beetle resistance in a wild potato, Solanum berthaultii. J. Econ. Entomol. 75: 368-372.

Duncan, D. B. 1955. Multiple range and multiple $F$ tests. Biometrics 11: 1-42.

Forgash, A. J. 1981. Insecticide resistance of the Colorado potato beetle, Leptinotarsa decemlineata (Say), pp. 34-46. In J. Lashomb and R. Casagrande [eds.], Advances in potato pest management. Hutchinson Ross Publishing Co., Stroudsbourg, Pa.

Gauthier, N. L., R. N. Hofmaster, and M. Semel. 1981. History of Colorado potato beetle control, pp. 13-33. In Ibid.

Gibson, R. W., and R. H. Turner. 1977. Insect-trapping hairs on potato plants. PANS 22: 272-277.

Harcourt, D. G. 1963. Population dynamics of Leptinotarsa decemlineata (Say) in Eastern Ontario. I. Spatial pattern and transformation of field counts. Can. Entomol. 95: 813-820.

Hare, J. D. 1980. Contact toxicities of ten insecticides to Connecticut populations of the Colorado potato beetle. J. Econ. Entomol. 73: 230-231.

Hsiao, T. H. 1978. Host plant adaptations among geographic populations of the Colorado potato beetle. Entomol. Exp. Appl. 24: 237-247.

Latheef, M. A., and D. G. Harcourt. 1974. The dynamics of Leptinotarsa decemlineata populations on tomato. Ibid. 17: 67-76.

Little, T. M., and F. J. Hills. 1978. Agricultural experimentation-design and analysis. John Wiley and Sons, New York.
Poston, F. L., L. P. Pedigo, and S. M. Welch. 1983. Economic injury levels: reality and practicality. Bull. Entomol. Soc. Am. 19: 49-53.

Ryan, J. D., P. Gregory, and W. M. Tingey. 1982. Phenolic oxidase activities in glandular trichomes of Solanum berthaultii. Phytochemistry 21: 1885-1887.

Tingey, W. M. 1981. Potential for plant resistance in management of arthropod pests, pp. 268-288. In J. Lashomb and R. Casagrande [eds.], Advances in potato pest management. Hutchinson Ross Publishing Co., Stroudsbourg, Pa.

1984. Glycoalkaloids as pest resistance factors. Am. Potato J. 61: 157-167.

Tingey, W. M., and R. W. Gibson. 1978. Feeding and mobility of the potato leafhopper impaired by glandular trichomes of Solanum berthaultii and $S$. polyadenium. J. Econ. Entomol. 71: 856-858.

Tingey, W. M., and J. E. Laubengayer. 1981. Defense against the green peach aphid and potato leafhopper by glandular trichomes of Solanum berthaultii. Ibid. 74: 721-725.

Tingey, W. M., and S. L. Sinden. 1982. Glandular pubescence, glycoalkaloid composition and resistance to the green peach aphid, potato leafhopper and potato fleabeetle in Solanum berthaultii. Am. Potato J. 59: 95-106.

Tingey, W. M., R. L. Plaisted, J. E. Laubengayer, and S. A. Mehlenbacher. 1982. Green peach aphid resistance by glandular trichomes in Solanum tuberosum $\times S$. berthaultii hybrids. Ibid. 59: 241-25l.

de Wilde, J., W. Bongers, and H. Schooneveld. 1969. Effects of host plant age on phytophagous insects. Entomol. Exp. Appl. 12: 714-720.

Received for publication 8 May 1984; accepted 12 February 1985. 